\title{
Practical guide to exocrine pancreatic insufficiency - Breaking the myths
}

\author{
Maarten R. Struyvenberg, Camilia R. Martin and Steven D. Freedman ${ }^{*}$
}

\begin{abstract}
Background: Exocrine pancreatic insufficiency (EPI) is characterized by a deficiency of exocrine pancreatic enzymes, resulting in malabsorption. Numerous conditions account for the etiology of EPI, with the most common being diseases of the pancreatic parenchyma including chronic pancreatitis, cystic fibrosis, and a history of extensive necrotizing acute pancreatitis. Treatment for EPI includes dietary management, lifestyle changes (i.e., decrease in alcohol consumption and smoking cessation), and pancreatic enzyme replacement therapy.

Discussion: Many diagnostic tests are available to diagnose EPI, however, the criteria of choice remain unclear and the causes for a false-positive test are not yet understood. Despite multiple studies on the treatment of EPI using exogenous pancreatic enzymes, there remains confusion amongst medical practitioners with regard to the best approach to diagnose EPI, as well as dosing and administration of pancreatic enzymes.
\end{abstract}

Summary: Appropriate use of diagnostics and treatment approaches using pancreatic enzymes in EPI is essential for patients. This opinion piece aims to address the existing myths, remove the current confusion, and function as a practical guide to the diagnosis and treatment of EPI.

Keywords: Exocrine pancreatic insufficiency, Lipase, Steatorrhea, Fat malabsorption, Pancreatic enzyme replacement therapy, Pancreatic enzymes

\section{Background}

Exocrine pancreatic insufficiency (EPI) is defined by a deficiency of exocrine pancreatic enzymes resulting in an inability to maintain normal digestion. This inadequate digestion with nutrient and, especially, fat malabsorption occurs when intraduodenal levels of lipase fall below $5-10 \%$ of normal enzyme output [1], leading to pancreatic steatorrhea, weight loss, and a potential decrease in quality of life [2-5]. Furthermore, in EPI, due to cystic fibrosis (CF) or chronic pancreatitis, there is decreased bicarbonate output causing a lower intestinal $\mathrm{pH}$, which precipitates bile salt acids and impairs micelle formation of fats $[6,7]$. Fat maldigestion is compounded by decreased pancreatic secretion of lipase and colipase, further dampening hydrolysis of intraluminal fat.

A myriad of tests for EPI have been developed over the years, however, the choice of which to use remains unclear as does the understanding of causes for a falsepositive test. In addition, there is significant confusion

* Correspondence: sfreedma@bidmc.harvard.edu

Beth Israel Deaconess Medical Center, 330 Brookline Ave., Dana 501, Boston, MA 02215, USA

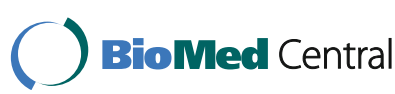

over dosing and administration of pancreatic enzymes. This opinion piece aims to address the existing myths, remove the current confusion, and function as a practical guide to the diagnosis and treatment of EPI.

\section{Discussion}

Myth: EPI occurs only with more than $90 \%$ loss of exocrine pancreatic function

Expert opinion: EPI represents a graded response rather than a precise cut-off in pancreatic function and thus patients may benefit from early testing

A leading cause of EPI is chronic pancreatitis [8]. Other pancreatic causes include a history of extensive necrotizing acute pancreatitis, pancreatic cancer, pancreatic surgery, and CF. Non-pancreatic causes are celiac disease, diabetes mellitus, Crohn's disease, gastric surgery, short bowel syndrome, and Zollinger-Ellison syndrome [9]. Symptoms of EPI can include steatorrhea (clay-colored, loose, greasy, foul-smelling large stools), 
abdominal discomfort, bloating, and weight loss. Although floating stools are often thought of being indicative of steatorrhea, they are not; rather sticking to the toilet bowl is a more specific sign.

\section{Chronic pancreatitis}

Chronic pancreatitis is an ongoing inflammatory process with irreversible morphological changes to the pancreas and a gradual loss in pancreatic parenchyma. There are three major groups of mutations that account for chronic pancreatitis (PRSS1, SPINK1, and CFTR). Theories of pathogenesis include oxidative stress, toxicmetabolic derangements, loss of ductal function or obstruction, and necrosis-fibrosis [10].

In chronic pancreatitis, approximately $20 \%$ of patients develop EPI over time as a result of progressive loss of acinar cell function [11]. Layer et al. [11] found that the median duration from the onset of symptomatic disease to EPI was significantly longer in early-onset chronic pancreatitis (median age of onset being 19.2 years) than in late-onset idiopathic chronic pancreatitis (median age of 56.2 years) or alcoholic pancreatitis (median age of 13.1 years).

\section{Cystic fibrosis}

$\mathrm{CF}$ is an autosomal recessive disorder caused by a mutation of the gene that encodes for a chloride channel called the cystic fibrosis transmembrane conductance regulator (CFTR). In ductal epithelial cells, CFTR is highly expressed and functions to transport fluid and anions into the lumen [12]. Dysfunction of the CFTR gene leads to a decrease in luminal fluid volume and decreased $\mathrm{pH}$, resulting in protein precipitation within the ductal lumen and loss of normal acinar cell function.

EPI is most commonly observed at birth or soon after due to in utero exocrine pancreatic damage. Waters et al. [13] showed that, during newborn screening, $63 \%$ of infants with CF are exocrine insufficient and almost 30\% of the pancreas-sufficient group will become exocrine insufficient over the next 36 months. Individuals with class IV, V, or VI mutations (less severe CFTR mutations and hence some preserved CFTR function), tend to suffer from EPI later in life $[14,15]$. Corey et al. [16] compared 1000 patients from CF clinics in Boston and Toronto and demonstrated that prolonged untreated EPI is associated with a worse long-term outcome and that patients maintained on a high fat diet (100 g per day) with higher doses of exogenous pancreatic enzymes did better than those on a low fat, lower pancreatic enzyme regimen. Overall, pancreatic insufficiency requiring lifelong pancreatic exocrine replacement therapy (PERT) is found in about $85 \%$ of CF patients [12].

A rare complication of PERT is seen only in patients with $\mathrm{CF}$ on very high doses of enzymes. Fitzsimmons et al. [17] found that, in children with CF, there was a strong correlation between high daily doses of PERT and the development of fibrosing colonopathy. However, this represents a small case series published in NEJM in 1997, which were not biopsy proven with very few cases reported since then. Factors related to $\mathrm{CF}$, including thick intestinal secretions, dosing of PERT, and agents in the enteric coating of the pancrelipase preparations may be the precipitating factors causing this complication [18]. Therefore, it has been recommended that, in children and adults with CF, the daily dose should remain below 2500 lipase units/kg of body weight per meal or 10000 lipase units/kg of body weight per day $[17,19]$.

\section{Post pancreatic surgery}

Factors that contribute to EPI following pancreatic surgery are a decrease in pancreatic tissue volume, extensive denervation following lymph node dissection, and surgically altered anatomy [6]. Conditions such as pancreatic cancer, intraductal papillary mucinous neoplasms, premalignant mucinous cystic lesions, and benign tumors of the pancreas may all lead to EPI via obstruction of the pancreatic duct. The degree of EPI following pancreatic surgery is dependent on the extent of pancreatic resection combined with the degree of residual pancreatic parenchymal function with full manifestation of EPI seen following a total pancreatectomy $[20,21]$. The mechanism of EPI in patients undergoing a Whipple procedure may be related to a mistiming of secreted endogenous pancreatic enzymes mixing with chyme.

Large systematic reviews report a $19-80 \%$ incidence of EPI following a distal pancreatectomy [22-25]; however, this wide variation may be in part a result of the different diagnostic methods employed [22, 26]. Postoperative incidence of EPI after Whipple surgery is 5698\% [23, 24, 27-29]. In addition, Halloran et al. [28] analyzed 40 patients following resection for pancreatic malignancy and found that EPI was common and sustained after surgery, but was not associated with significant symptoms. These patients with newly developed EPI, however, did have a tendency towards poorer quality of life.

\section{Celiac disease}

Celiac disease is a chronic inflammatory intestinal disorder that may occur in genetically predisposed people triggered by the ingestion of gluten. This disease has a United States and British prevalence of approximately $1 \%[30,31]$. In celiac disease, although exocrine pancreatic function is intrinsically normal, reduced levels of cholecystokinin release as a result of the duodenal villous atrophy, accounts for impaired gall bladder contraction and reduced exocrine pancreatic secretion [32, 33]. 


\section{Diabetes mellitus}

The term islet-acinar axis has been used to describe the endocrine-exocrine relationship within the pancreas, whereby there is a vascular and physiologic interaction between these different cell types [34]. Pathophysiologically, diabetes mellitus can predispose to EPI and, conversely, longstanding EPI can be associated with diabetes [35-39]. In diabetes, there are several possible causes which can account for EPI - the lack of the trophic action of insulin (and potentially of glucagon and somatostatin) on acinar cells, autoimmune damage of islet cells, causing destruction of both endocrine and exocrine tissue, and decreased exocrine pancreatic secretion as a complication of diabetic neuropathy $[36,37]$. Therefore, the lack of insulin production and the autoimmunity in type I diabetes explain the higher observed prevalence of EPI compared to those with type II diabetes (about 60\% vs. 30\%) [38]. In addition, a recent article by Soave et al. [39] showed that the lower the immunoreactive trypsinogen levels at birth in newborns with $\mathrm{CF}$, reflecting more severe exocrine pancreatic disease in utero, the earlier in life they developed CF-related endocrine disease (diabetes).

\section{All infants}

Based on the study by Lebenthal and Lee [40] indicating that the duodenal fluid of newborns and infants contained no amylase and negligible lipase at least for the first month of life, all healthy term infants are exocrine pancreatic insufficient. Normally, this is compensated for by amylase and lipase present in breastmilk. However, in formula-fed infants, EPI would be expected. In fact, a recent study by Martin et al. [41] confirmed that formula-fed preterm infants had impaired fatty acid absorption evident through 6 or more weeks postnatal age compared to breastmilk-fed infants, and this is consistent with limited pancreatic lipase production by the pancreas [41]. Thus, all infants, both term and preterm, represent the largest population of individuals with EPI. The clinical implications of developmental pancreatic insufficiency in non-breast-fed infants is unknown, but may play a role in early nutrient deficits in critically ill newborns such as the preterm infant.

\section{How do we test for exocrine pancreatic insufficiency?}

Myth: Routinely checking for EPI in patients with chronic diarrhea, using fecal elastase, is a useful and effective diagnostic approach with values 100-200 $\mathrm{\mu g} / \mathrm{g}$ of stool reflecting mild to moderate pancreatic insufficiency and $100 \mu \mathrm{g} / \mathrm{g}$ of stool indicating severe EPI

Expert opinion: Routinely checking for EPI in patients with chronic diarrhea, using fecal elastase, is unreliable in the absence of testing a formed stool
A multitude of tests for EPI have been developed over the past several decades and classified as direct versus indirect measures of exocrine pancreatic function. However, many of these have poor sensitivity or specificity (e.g. serum trypsin levels, qualitative stool fat) and/or are available at only limited centers such as with the ${ }^{13} \mathrm{C}$ mixed triglyceride $\left({ }^{13} \mathrm{C}\right.$-MTG) breath test.

\section{2-hour fecal fat test}

The gold standard has been the 72-hour stool collection while the patient consumes a diet containing $100 \mathrm{~g}$ of fat per day. Fat malabsorption is diagnosed at $>7 \mathrm{~g}$ of fat per $100 \mathrm{~g}$ of stool per day, with severe steatorrhea at $\geq 15 \mathrm{~g}$ per day [18]. Unfortunately, this test is timeconsuming and not easily tolerated due to bloating, abdominal discomfort, flatulence, and worsening steatorrhea. Additionally, errors can occur in stool collections and recording of fat intake [42]. Diseases that impact mucosal fatty acid uptake, such as Crohn's disease, bacterial overgrowth, and short bowel syndrome, can cause abnormal values despite normal exocrine pancreatic function. However, the 72-hour stool collection has served to measure the effectiveness of PERT in EPI [43] for United States Food and Drug Administration (FDA) approval of PERTs.

\section{Fecal elastase test}

The pancreas produces pancreatic elastase 1 , which is a highly stable enzyme during intestinal transit [44]. This proteolytic enzyme can be measured in a fecal sample by an enzyme-linked immunosorbent assay $[45,46]$. Because pancreatic elastase is highly stable during intestinal transit, the fecal concentration correlates well with exocrine pancreatic secretion [45]. Diagnostic testing using fecal elastase has some advantages over other tests because it does not require a timed stool collection or special diet, has a high negative predictive value, and has a high sensitivity in moderate to severe EPI when formed stools are analyzed [8, 42, 47, 48]. The reference range of less than $200 \mu \mathrm{g} / \mathrm{g}$ feces can be applied to both children and adults for the diagnosis of EPI [44, 45, 49]. Some consider values less than $100 \mu \mathrm{g} / \mathrm{g}$ feces as diagnostic of EPI, with fecal elastase values between 100 and $200 \mu \mathrm{g} / \mathrm{g}$ to be indeterminate and difficult to interpret [50].

In mild to moderate EPI, diagnostic testing using fecal elastase has a lower sensitivity (as low as 30\%) and specificity, possibly resulting in an underestimation of EPI $[45,51-53]$. In childhood, however, fecal elastase is a useful noninvasive screening test for EPI, demonstrating a negative predictive value of $99 \%$ for ruling out EPI [42]. Since fecal elastase is measured as a concentration in stool, watery stools will almost invariably result in low elastase values being measured and thus this non-invasive, 
pancreatic function test should be performed in a clinical setting where EPI is suspected and a formed stool can be analyzed. This has replaced the more cumbersome 72hour fecal fat test. In addition, PERTs do not have to be stopped for fecal elastase testing since the porcine enzymes do not cross react with the human fecal elastase antibody.

\section{Treatment of exocrine pancreatic insufficiency}

\section{Myth: PERT should be started at the lowest dose available and taken any time before a meal and at bedtime}

Expert opinion: Titrate the dose of PERT to the presumptive degree of PERT and administer PERT with the first bite of a meal, and consider adding extra enzymes during or towards the end of the meal

\section{Dietary management and lifestyle changes}

Fat malabsorption is the predominant cause of the symptoms of pancreatic steatorrhea resulting in weight loss as well as deficiencies of fat-soluble vitamins A, D, $\mathrm{E}$, and $\mathrm{K}$. In patients with chronic pancreatitis, a low fat diet has been the recommendation in order to minimize the pain of this disease and, in conjunction with PERT, to effectively treat steatorrhea. However, in patients with $\mathrm{CF}$, a high fat diet in conjunction with increased amounts of PERTs has been shown to improve the associated CF lung disease and thus low fat diets are no longer advocated in this disease. Fat soluble vitamins A, D, $\mathrm{E}$, and $\mathrm{K}$ should be supplemented if indicated, and taken with PERT [54]. Consulting a dietitian is helpful to assess nutritional adequacy [55]. In addition, smoking has been proven to be a risk factor in acute pancreatitis, chronic pancreatitis, pancreatic cancer [56], and to be associated with reduced exocrine pancreatic function [57]. Therefore, smoking and alcohol cessation is recommended in EPI due to chronic pancreatitis.

\section{Pancreatic enzyme replacement therapy}

The elimination of malabsorption, reduction of maldigestion-related symptoms, and the prevention of malnutrition-related morbidity and mortality is the goal for PERT [55]. This is most evident in CF, where prior to the availability of PERT, infants died within the first year of life. Prior to 2010, pancreatic enzymes were not FDA regulated and had variable consistency of activity. As a result, in 2010, the FDA mandated approval of all prescribed formulations of PERT. It should be noted that the clinical trials were relatively small (less than 40 subjects) and tested in subjects who were known to respond to PERTs. All pancreatic enzyme preparations are extracts from porcine pancreas (pancrelipase) and are available in preparations encapsulated in minimicrospheres or microtablets, which vary in particle size and $\mathrm{pH}$-related release kinetics [58]. Enteric-coated pancreatic microspheres are designed to be acid resistant and $\mathrm{pH}$-sensitive to protect lipase from denaturation by gastric acid. Unfortunately, confusion has arisen due to the many different dosage strengths of PERTs [59] (Table 1).

Enteric-coated pancreatic enzymes are most effective at a $\mathrm{pH}>6$. However, in patients with $\mathrm{CF}$, the duodenal $\mathrm{pH}$ is $<6$ [60]. The use of acid-suppression medications can increase gastric $\mathrm{pH}$ levels and theoretically improve the efficacy of PERT and decrease EPI symptoms [61, 62]. Current data may suggest a trial of acid blockers in patients with CF who have refractory steatorrhea [61-65]. However, a recent retrospective study demonstrated no improvement of the coefficient of fat absorption (72-hour fecal fat test) when using a proton pump inhibitor in pediatric patients with CF [66].

Uncoated exogenous pancreatic enzymes, such as Viokase (Aptalis Pharma), are thought to mix well with intragastric nutrients and rapidly release high duodenal lipase amounts for fat digestion [58]. The addition of acid-suppression medications is required to prevent degradation of non-enteric coated pancreatic enzymes [58]. Only non-enteric pancreatic enzymes have been shown to improve the pain in a subset of patients with chronic pancreatitis. The use of unprotected exogenous enzymes in combination with enteric-coated enzymes has previously been recommended for the treatment of refractory EPI [58, 67]; however, Kalnins et al. [68] showed no improvement in nutrient digestion (fecal fat, energy, and nitrogen output) when unprotected pancreatic enzymes were added to the conventional enteric-coated enzymes in 14 pediatric patients with $\mathrm{CF}$.

\section{Dosing and frequency of PERT administration}

Dosing and frequency of administration are difficult aspects of PERT treatment since different entericcoated microspheres are not bioequivalent in vitro [69-71], and there are not enough clinical studies between preparations to define in vivo bioavailability. In these in vitro studies, the preparations varied in

Table 1 Current Food and Drug Administration (FDA) approved pancreatic enzyme replacement therapies (PERTs)

\begin{tabular}{ll}
\hline Brand & Units of lipase \\
\hline Creon & $3000 ; 6000 ; 12,000 ; 24,000 ; 36,000$ \\
Zenpep & $3000 ; 5000 ; 10,000 ; 15,000 ; 20,000 ; 25,000$ \\
Pancreaze & $4200 ; 10,500 ; 16,800 ; 21,000$ \\
Ultresa & 13,$800 ; 20,700 ; 23,000$ \\
Viokase & 10,$440 ; 20,880$ (requires acid suppression) \\
Pertzye & $8000 ; 16,000$ \\
\hline
\end{tabular}


dissolution time (49-71 min half-life time) and in optimum $\mathrm{pH}$ ( $\mathrm{pH}$ 5.0-5.8).

Several countries have recommended different doses of PERT. The Australasian Pancreatic Club [72], The Italian Association for the Study of the Pancreas [8], and The Spanish Pancreatic Club [73] recommend 25,00050,000 lipase units per main meal in adults. Unfortunately, the evidence for these recommendations is relatively weak as emphasized by The Australasian Pancreatic Club in their recent study on the management of pancreatic exocrine insufficiency [72]. In addition, a study from the Netherlands by Sikkens et al. [74] found that $70 \%(n=161)$ of the patients with EPI caused by chronic pancreatitis were under-treated and reported steatorrhea-related symptoms, despite PERT (median enzyme intake of 6 capsules, 25,000 lipase units per day). These differences in recommendations demonstrate the significant confusion over dosing and administration amongst medical practitioners.

Likewise, there is no consensus over frequency of PERT administration. In 1977, DiMagno et al. [75] demonstrated that administration of PERT during a meal was as effective as hourly administration over the day to decrease steatorrhea. Other recommendations based on several reviews are to take $50 \%$ of the exogenous pancreatic enzymes at the beginning of the meal and 50\% half-way through [76], pancreatic enzymes during or immediately following the meal [77], or lastly, $25 \%$ of the enzymes with the first bite, $50 \%$ during the meal, and $25 \%$ with the last bite [78]. In addition, a recent randomized three-way crossover study of 24 patients using 40,000 lipase units per meal compared three different administration schedules with PERT before meals, during meals, or after meals using the ${ }^{13} \mathrm{C}$-MTG breath test to measure fat absorption [79]. The percentage of patients who normalized fat digestion was $50 \%$, $54 \%$, and $63 \%$, respectively. Thus, no statistically significant differences were found between different administration schedules, however, they did recommend giving PERT during or after meals.

In a patient with suspected EPI with a known history of pancreatic disease, empiric therapy with PERTs may be indicated without formal testing. A clear response would be both diagnostic for EPI as well as therapeutic. In addition, if there is a poor response to PERT, one should consider concurrent gastrointestinal comorbidities such as lactose intolerance, enteric bacterial infection, parasites (especially giardia), small intestinal bacterial overgrowth, biliary disease (cholestasis), colitis, celiac disease, short bowel syndrome, and Crohn's disease [80]. Other reasons could be insufficient dosing, lack of compliance, inadequate timing of PERT administration, and poor diet (Table 2).

PERT should be taken with the first bite of a meal and consider adding extra enzymes during or towards the
Table 2 Treatment strategies for lack of response to pancreatic enzyme replacement therapy (PERT)

\begin{tabular}{l}
\hline Treatment strategies \\
- Increase dosage \\
- Check compliance with the patient \\
- Consider adding enzymes during and towards end of meal \\
- Consider microspheres, possibly adding a rapid release enzyme \\
preparation \\
- Look for evidence of concurrent gastrointestinal disorder
\end{tabular}

end of the meal. Thus, if consumption of a meal is less than $15 \mathrm{~min}$, all enzymes can be taken at the beginning of the meal; for a 15- to 30-minute meal, we suggest taking half the enzyme capsules with the first bite and the other half in the middle of the meal; for more than 30 minutes, we recommend taking one third at the beginning, one third in the middle and one third at the end. The rationale for taking pancreatic enzymes throughout the meal is to mimic the action of our own endogenous pancreatic enzymes, where secretion from the gland occurs throughout a meal. Specifically, the more food that is ingested and/or the grater the amount of fat in the diet, the higher the amount of endogenous pancreatic enzyme secretion; thus, the number of PERT capsules consumed should reflect this. Table 3 gives a suggested clinical overview of PERT dosing for different age groups $[17,19,80]$.

\section{Summary}

Since the required FDA approval of PERT in 2010, we now have reliable medications for the treatment of EPI. These therapies have improved signs and symptoms related to EPI such as steatorrhea and abdominal discomfort, weight loss, malnutrition, and possibly even quality of life. PERT is lifesaving in CF, since prior to PERT, babies with CF died of malnutrition within the first year of life. However, there is still much confusion amongst

Table 3 Pancreatic enzyme replacement therapy (PERT) suggested dosing in different age groups

\begin{tabular}{ll}
\hline Age group & Units of lipase \\
\hline Infant & $2000-4000$ units $/ 120 \mathrm{~mL}$ formula \\
& or breastmilk \\
& $1000 \mathrm{units} / \mathrm{kg} / \mathrm{meal}$ \\
Child age $<4$ years & $500 \mathrm{units} / \mathrm{kg} / \mathrm{snack}$ \\
& $500 \mathrm{units} / \mathrm{kg} / \mathrm{meal}$ \\
Child age $\geq 4$ years & $250 \mathrm{units} / \mathrm{kg} / \mathrm{snack}$ \\
& $50,000 \mathrm{units} / \mathrm{meal}$ \\
Adult starting dose & 25,000 units $/ \mathrm{snack}$ \\
Adult maximum dose & 150,000 units $/$ meal \\
& 70,000 units/snack \\
\hline
\end{tabular}


medical practitioners over the best diagnostic approach as well as dosing and administration of PERT. Many countries have developed different guidelines regarding dosing and administration of PERT, calling out for a consensus and a practical guide for the diagnosis and treatment of EPI using exogenous pancreatic enzymes. In addition, evidence supports that patients are being undertreated with PERT and may potentially benefit from more adequate therapy.

There are two areas that need emphasis. First, physicians need to know when to test for EPI and agree on using the same methods for diagnosing EPI. Over the last decade, there has been a change in diagnostic approach for EPI from the unreliable qualitative stool test and the cumbersome 72-hour fecal fat collection, to the more sensitive, but less specific, fecal elastase test, especially in patients with mild to moderate EPI. Many physicians do not realize the need to have formed stools analyzed and thus, in chronic diarrhea, this may be problematic. Ultimately, what is critical is the early diagnosis and optimization of treatment of EPI.

Second, there must be optimization of the currently available therapies for EPI. The existing studies vary on recommendations for dosing of exogenous pancreatic enzymes ranging from 25,000 to 80,000 lipase units per main meal, and there is uncertainty about administration of PERT before, during, or after the meal. In addition, the treatment goals differ from reducing pancreatic steatorrhea and elimination of maldigestion and malabsorption, to the prevention of malnutrition-related morbidity and mortality. This is all complicated by the myriad of pancreatic enzyme formulations at a wide array of dosing strengths. Thus, it is not surprising that confusion amongst physicians exists over the optimal dosage, administration schedule, and what to aim for in PERT.

Our recommendations for PERT are: (1) titrate the dose of PERT to the presumptive degree of PERT, (2) administer PERT with the first bite of a meal and consider adding extra enzymes during or towards the end of the meal, (3) consider using microspheres, possibly adding a rapid release enzyme preparation and/or acid-blockade, and (4) adjusting the dose to the fat content of the meal.

\footnotetext{
Abbreviations

${ }^{13}$ C-MTG: ${ }^{13}$ C-mixed triglyceride; CF: cystic fibrosis; CFTR: cystic fibrosis transmembrane conductance regulator; EPI: exocrine pancreatic insufficiency; FDA: Food and Drug Administration; PERT: pancreatic enzyme replacement therapy; PRSS1: cationic trypsinogen; SPINK1: serine peptidase inhibitor Kazal Type 1
}

\section{Acknowledgements}

Not applicable.

Funding

Not applicable.

Availability of data and material

Not applicable.
Authors' contributions

MRS, Dr. SDF, and Dr. CRM contributed equally to the review of the literature on EPI and writing and revising of the manuscript. All authors read and approved the final manuscript.

\section{Authors' information}

MRS is a final year medical student from The University of Groningen, The Netherlands, working with Dr. Freedman at Beth Israel Deaconess Medical Center. SDF is the Chief of the Division of Translational Research and Professor of Medicine at Harvard Medical School. He is Director of The Pancreas Center and is a worldwide leading expert on pancreatic disease and cystic fibrosis. CRM is Associate Director of the Neonatal Intensive Care Unit at Beth Israel Deaconess Medical Center, Director of Cross-disciplinary Partnerships, Division of Translational Research, and Associate Professor of Pediatrics, Harvard Medical School. She is an international expert on fatty acids and nutrition in preterm infants.

\section{Competing interests}

The authors declare that they have no competing interests.

\section{Consent for publication}

Not applicable.

Ethics approval and consent to participate Not applicable.

Received: 8 September 2016 Accepted: 9 January 2017

Published online: 10 February 2017

\section{References}

1. DiMagno EP, Go VL, Summerskill WH. Relations between pancreatic enzyme outputs and malabsorption in severe pancreatic insufficiency. N Engl J Med. 1973;288:813-5.

2. Fieker A, Philpott J, Armand M. Enzyme replacement therapy for pancreatic insufficiency: Present and future. Clin Exp Gastroenterol. 2011:4:55-73.

3. Whitcomb DC, Lehman GA, Vasileva G, Malecka-Panas E, Gubergrits N, Shen Y, Sander-Struckmeier S, Caras S. Pancrelipase delayed-release capsules (CREON) for exocrine pancreatic insufficiency due to chronic pancreatitis or pancreatic surgery: A double-blind randomized trial. Am J Gastroenterol. 2010;105:2276-86.

4. Pezzilli R, Morselli Labate AM, Ceciliato R, Frulloni L, Cavestro GM, Comparato G, Ferri B, Corinaldesi R, Gullo L. Quality of life in patients with chronic pancreatitis. Dig Liver Dis. 2005;37:181-9.

5. Ferrone M, Raimondo M, Scolapio JS. Pancreatic enzyme pharmacotherapy. Pharmacotherapy. 2007;27:910-20.

6. Ghaneh P, Neoptolemos JP. Exocrine pancreatic function following pancreatectomy. Ann N Y Acad Sci. 1999;880:308-18.

7. Guarner L, Rodríguez R, Guarner F, Malagelada JR. Fate of oral enzymes in pancreatic insufficiency. Gut. 1993;34:708-12.

8. Frulloni L, Falconi M, Gabbrielli A, Gaia E, Graziani R, Pezzilli R, Uomo G, Andriulli A, Balzano G, Benini L, Calculli L, Campra D, Capurso G, Cavestro GM, De Angelis C, Ghezzo L, Manfredi R, Malesci A, Mariani A, Mutignani M, Ventrucci M, Zamboni G, Amodio A, Vantini I. Italian consensus quidelines for chronic pancreatitis. Dig Liver Dis. 2010;42 Suppl 6:S381-406.

9. Keller J, Layer P. Human pancreatic exocrine response to nutrients in health and disease. Gut. 2005;54:1-28.

10. Stevens T, Conwell DL, Zuccaro G. Pathogenesis of chronic pancreatitis: an evidence-based review of past theories and recent developments. Am J Gastroenterol. 2004;99:2256-70.

11. Layer P, Yamamoto H, Kalthoff L, Clain JE, Bakken L, DiMagno EP. The different courses of early- and late-onset idiopathic and alcoholic chronic pancreatitis. Gastroenterology. 1994;107:1481-7.

12. Olivier AK, Gibson-Corley KN, Meyerholz DK. Animal models of gastrointestinal and liver diseases. Animal models of cystic fibrosis: gastrointestinal, pancreatic, and hepatobiliary disease and pathophysiology. Am J Physiol Gastrointest Liver Physiol. 2015;308:G459-71.

13. Waters DL, Dorney SF, Gaskin KJ, Gruca MA, O'Halloran M, Wilcken B. Pancreatic function in infants identified as having cystic fibrosis in a neonatal screening program. N Engl J Med. 1990;322:303-8. 
14. Bodewes FAJA, Verkade HJ, Taminiau JAJM, Borowitz D, Wilschanski M Cystic fibrosis and the role of gastrointestinal outcome measures in the new era of therapeutic CFTR modulation. J Cyst Fibros. 2015;14:169-77.

15. Ledder O, Haller W, Couper RT, Lewindon P, Oliver M. Cystic fibrosis: an update for clinicians. Part 2: hepatobiliary and pancreatic manifestations. J Gastroenterol Hepatol. 2014;29:1954-62.

16. Corey M, McLaughlin FJ, Williams M, Levison H. A comparison of survival, growth, and pulmonary function in patients with cystic fibrosis in Boston and Toronto. J Clin Epidemiol. 1988;41:583-91.

17. FitzSimmons SC, Burkhart GA, Borowitz D, Grand RJ, Hammerstrom T, Durie PR, Lloyd-Still JD, Lowenfels AB. High-dose pancreatic-enzyme supplements and fibrosing colonopathy in children with cystic fibrosis. N Engl J Med. 1997;336:1283-9.

18. Nakajima K, Oshida H, Muneyuki T, Kakei M. Pancrelipase: An evidencebased review of its use for treating pancreatic exocrine insufficiency. Core Evid. 2012;7:77-91.

19. Lloyd-Still JD. Cystic fibrosis and colonic strictures. A new "iatrogenic" disease. J Clin Gastroenterol. 1995;21(1):2-5.

20. Falconi M, Mantovani W, Crippa S, Mascetta G, Salvia R, Pederzoli P. Pancreatic insufficiency after different resections for benign tumours. $\mathrm{Br} J$ Surg. 2008;95:85-91.

21. Tanaka M, Chari S, Adsay V, Fernandez-del Castillo C, Falconi M, Shimizu M Yamaguchi K, Yamao K, Matsuno S. International consensus guidelines for management of intraductal papillary mucinous neoplasms and mucinous cystic neoplasms of the pancreas. Pancreatology. 2006;6:17-32.

22. lacono C, Verlato G, Ruzzenente A, Campagnaro T, Bacchelli C, Valdegamberi A, Bortolasi L, Guglielmi A. Systematic review of central pancreatectomy and meta-analysis of central versus distal pancreatectomy. Br J Surg. 2013;100:873-85.

23. Schnelldorfer T, Lewin DN, Adams DB. Operative management of chronic pancreatitis: longterm results in 372 patients. J Am Coll Surg. 2007:204:1039-45.

24. Belyaev O, Herzog T, Chromik AM, Meurer K, Uhl W. Early and late postoperative changes in the quality of life after pancreatic surgery. Langenbecks Arch Surg. 2013;398:547-55.

25. Speicher JE, Traverso LW. Pancreatic exocrine function is preserved after distal pancreatectomy. J Gastrointest Surg. 2010;14:1006-11.

26. Phillips ME. Pancreatic exocrine insufficiency following pancreatic resection. Pancreatology. 2015;15:449-55.

27. Sikkens ECM, Cahen DL, de Wit J, Looman CWN, van Eijck C, Bruno MJ. A prospective assessment of the natural course of the exocrine pancreatic function in patients with a pancreatic head tumor. J Clin Gastroenterol. 2014;48:e43-6.

28. Halloran CM, Cox TF, Chauhan S, Raraty MGT, Sutton R, Neoptolemos JP, Ghaneh P. Partial pancreatic resection for pancreatic malignancy is associated with sustained pancreatic exocrine failure and reduced quality of life: A prospective study. Pancreatology. 2012;11:535-45.

29. Matsumoto J, Traverso LW. Exocrine function following the Whipple operation as assessed by stool elastase. J Gastrointest Surg. 2006;10:1225-9.

30. West J, Logan RFA, Hill PG, Lloyd A, Lewis S, Hubbard R, Reader R, Holmes GKT, Khaw K-T. Seroprevalence, correlates, and characteristics of undetected coeliac disease in England. Gut. 2003;52:960-5.

31. Fasano A, Berti I, Gerarduzzi T, Not T, Colletti RB, Drago S, Elitsur Y, Green PHR, Guandalini S, Hill ID, Pietzak M, Ventura A, Thorpe M, Kryszak D, Fornaroli F, Wasserman SS, Murray JA, Horvath K. Prevalence of celiac disease in at-risk and not-at-risk groups in the United States: a large multicenter study. Arch Intern Med. 2003;163:286-92.

32. Deprez P, Sempoux C, Van Beers BE, Jouret A, Robert A, Rahier J, Geubel A Pauwels S, Mainguet P. Persistent decreased plasma cholecystokinin levels in celiac patients under gluten-free diet: Respective roles of histological changes and nutrient hydrolysis. Regul Pept. 2002;110:55-63.

33. Fraquelli M, Bardella MT, Peracchi M, Cesana BM, Bianchi PA, Conte D. Gallbladder emptying and somatostatin and cholecystokinin plasma levels in celiac disease. Am J Gastroenterol. 1999:94:1866-70.

34. Barreto SG, Carati CJ, Toouli J, Saccone GTP. The islet-acinar axis of the pancreas: more than just insulin. Am J Physiol Gastrointest Liver Physiol. 2010;299:G10-22.

35. Patel R, Yago MD, Mañas M, Victoria EM, Shervington A, Singh J. Mechanism of exocrine pancreatic insufficiency in streptozotocin-induced diabetes mellitus in rat: effect of cholecystokinin-octapeptide. Mol Cell Biochem. 2004:261:83-9.
36. Hardt PD, Ewald N. Exocrine pancreatic insufficiency in diabetes mellitus: A complication of diabetic neuropathy or a different type of diabetes? Exp Diabetes Res. 2011;2011:761950.

37. Ewald N, Kaufmann C, Raspe A, Kloer HU, Bretzel RG, Hardt PD. Prevalence of diabetes mellitus secondary to pancreatic diseases (type 3c). Diabetes Metab Res Rev. 2012;28:338-42.

38. Piciucchi M, Capurso G, Archibugi L, Delle Fave MM, Capasso M, Delle FG. Exocrine pancreatic insufficiency in diabetic patients: Prevalence, mechanisms, and treatment. Int J Endocrinol. 2015;2015:595649.

39. Soave D, Miller MR, Keenan K, Li W, Gong J, Ip W, Accurso F, Sun L, Rommens JM, Sontag M, Durie PR, Strug LJ. Evidence for a causal relationship between early exocrine pancreatic disease and cystic fibrosisrelated diabetes: a Mendelian randomization study. Diabetes. 2014;63:2114-9.

40. Lebenthal $E$, Lee PC. Development of functional responses in human exocrine pancreas. Pediatrics. 1980;66:556-60.

41. Martin CR, Cheesman A, Brown J, Makda M, Kutner AJ, DaSilva D, Zaman M, Freedman SD. Factors determining optimal fatty acid absorption in preterm infants. J Pediatr Gastroenterol Nutr. 2016;62:130-6.

42. Beharry S, Ellis L, Corey M, Marcon M, Durie P. How useful is fecal pancreatic elastase 1 as a marker of exocrine pancreatic disease? J Pediatr. 2002:141:84-90.

43. Berry AJ. Pancreatic enzyme replacement therapy during pancreatic insufficiency. Nutr Clin Pract. 2014;29:312-21.

44. Sziegoleit A, Krause E, Klör HU, Kanacher L, Linder D. Elastase 1 and chymotrypsin B in pancreatic juice and feces. Clin Biochem. 1989;22:85-9.

45. Löser C, Möllgaard A, Fölsch UR. Faecal elastase 1: a novel, highly sensitive, and specific tubeless pancreatic function test. Gut. 1996;39:580-6.

46. Leeds JS, Hopper AD, Hurlstone DP, Edwards SJ, Mcalindon ME, Lobo AJ, Donnelly MT, Morley S, Sanders DS. Is exocrine pancreatic insufficiency in adult coeliac disease a cause of persisting symptoms? Aliment Pharmacol Ther. 2007;25:265-71.

47. Witt H, Apte MV, Keim V, Wilson JS. Chronic pancreatitis: challenges and advances in pathogenesis, genetics, diagnosis, and therapy. Gastroenterology. 2007;132:1557-73.

48. Gullo L, Ventrucci M, Tomassetti P, Migliori M, Pezzilli R. Fecal elastase 1 determination in chronic pancreatitis. Dig Dis Sci. 1999:44:210-3.

49. Nissler K, Von Katte I, Huebner A, Henker J. Pancreatic elastase 1 in feces of preterm and term infants. J Pediatr Gastroenterol Nutr. 2001;33:28-31.

50. Lieb J-G. Pancreatic function testing: here to stay for the 21st century. World J Gastroenterol. 2008;14:3149.

51. Lankisch PG, Schmidt I, König H, Lehnick D, Knollmann R, Löhr M, Liebe S. Faecal elastase 1: not helpful in diagnosing chronic pancreatitis associated with mild to moderate exocrine pancreatic insufficiency. Gut. 1998;42:551-4.

52. Katschinski M, Schirra J, Bross A, Göke B, Arnold R. Duodenal secretion and fecal excretion of pancreatic elastase-1 in healthy humans and patients with chronic pancreatitis. Pancreas. 1997:15:191-200.

53. Glasbrenner B, Schön A, Klatt S, Beckh K, Adler G. Clinical evaluation of the faecal elastase test in the diagnosis and staging of chronic pancreatitis. Eur J Gastroenterol Hepatol. 1996:8(11):1117-20.

54. Sikkens ECM, Cahen DL, Koch AD, Braat H, Poley JW, Kuipers EJ, Bruno MJ. The prevalence of fat-soluble vitamin deficiencies and a decreased bone mass in patients with chronic pancreatitis. Pancreatology. 2013;13:238-42.

55. Lindkvist B. Diagnosis and treatment of pancreatic exocrine insufficiency. World J Gastroenterol. 2013;19:7258-66.

56. Yadav D, Lowenfels AB. The epidemiology of pancreatitis and pancreatic cancer. Gastroenterology. 2013;144:1252-61.

57. Law R, Parsi M, Lopez R, Zuccaro G, Stevens T. Cigarette smoking is independently associated with chronic pancreatitis. Pancreatology. 2010;10:54-9.

58. Trang T, Chan J, Graham DY. Pancreatic enzyme replacement therapy for pancreatic exocrine insufficiency in the 21(st) century. World J Gastroenterol. 2014;20:11467-85.

59. Food and Drug Administration. Updated questions and answers for healthcare professionals and the public: use an approved pancreatic enzyme product (PEP). 2012. http://www.fda.gov/Drugs/DrugSafety/ PostmarketDrugSafetylnformationforPatientsandProviders/ucm204745.htm Accessed 24 Aug 2016.

60. Gelfond D, Ma C, Semler J, Borowitz D. Intestinal pH and gastrointestinal transit profiles in cystic fibrosis patients measured by wireless motility capsule. Dig Dis Sci. 2013;58:2275-81. 
61. Heijerman HG, Lamers CB, Bakker W, Dijkman JH. Improvement of fecal fat excretion after addition of omeprazole to pancrease in cystic fibrosis is related to residual exocrine function of the pancreas. Dig Dis Sci. 1993;38:1-6.

62. Proesmans M, De Boeck K. Omeprazole, a proton pump inhibitor, improves residual steatorrhoea in cystic fibrosis patients treated with high dose pancreatic enzymes. Eur J Pediatr. 2003;162:760-3.

63. Francisco MP, Wagner MH, Sherman JM, Theriaque D, Bowser E, Novak DA. Ranitidine and omeprazole as adjuvant therapy to pancrelipase to improve fat absorption in patients with cystic fibrosis. J Pediatr Gastroenterol Nutr. 2002;35:79-83.

64. Tran TM, Van den Neucker A, Hendriks JJ, Forget P, Forget PP. Effects of a proton-pump inhibitor in cystic fibrosis. Acta Paediatr. 1998;87:553-8.

65. $\mathrm{Ng} \mathrm{SM}$, Franchini AJ. Drug therapies for reducing gastric acidity in people with cystic fibrosis. Cochrane Database Syst Rev. 2014;8, CD003424.

66. Woestenenk JW, van der Ent CK, Houwen RH. Pancreatic enzyme replacement therapy and coefficient of fat absorption in children and adolescents with cystic fibrosis. J Pediatr Gastroenterol Nutr. 2015;61:355-60.

67. Meyer JH, Lake R. Mismatch of duodenal deliveries of dietary fat and pancreatin from enterically coated microspheres. Pancreas. 1997;15:226-35.

68. Kalnins D, Corey M, Ellis L, Durie PR, Pencharz PB. Combining unprotected pancreatic enzymes with $\mathrm{pH}$-sensitive enteric-coated microspheres does not improve nutrient digestion in patients with cystic fibrosis. J Pediatr. 2005;146:489-93.

69. Case $\mathrm{CL}$, Henniges F, Barkin JS. Enzyme content and acid stability of entericcoated pancreatic enzyme products in vitro. Pancreas. 2005;30:180-3.

70. Aloulou A, Puccinelli D, Sarles J, Laugier R, Leblond Y, Carrière F. In vitro comparative study of three pancreatic enzyme preparations: dissolution profiles, active enzyme release and acid stability. Aliment Pharmacol Ther. 2008;27:283-92

71. Kraisinger M, Hochhaus G, Stecenko A, Bowser E, Hendeles L. Clinical pharmacology of pancreatic enzymes in patients with cystic fibrosis and in vitro performance of microencapsulated formulations. J Clin Pharmacol. 1994:34:158-66.

72. Working Party of the Australasian Pancreatic C, Smith RC, Smith SF, Wilson J, Pearce C, Wray N, Vo R, Chen J, Ooi CY, Oliver M, Katz T, Turner R, Nikfarjam M, Rayner C, Horowitz M, Holtmann G, Talley N, Windsor J, Pirola R, Neale R. Summary and recommendations from the Australasian guidelines for the management of pancreatic exocrine insufficiency. Pancreatology. 2016;16(2):164-80.

73. Martínez J, Abad-González A, Aparicio JR, Aparisi L, Boadas J, Boix E, de las Heras G, Domínguez-Muñoz E, Farré A, Fernández-Cruz L, Gómez L, Iglesias-García J, García-Malpartida K, Guarner L, Lariño-Noia J, Lluís F, López A, Molero X, Moreno-Pérez O, Navarro S, Palazón JM, Pérez-Mateo M, Sabater L, Sastre $Y$, Vaquero E, de-Madaria E. The Spanish Pancreatic Club recommendations for the diagnosis and treatment of chronic pancreatitis: Part 1 (diagnosis). Pancreatology. 2012;13:18-28.

74. Sikkens ECM, Cahen DL, Van Eijck C, Kuipers EJ, Bruno MJ. Patients with exocrine insufficiency due to chronic pancreatitis are undertreated: A Dutch national survey. Pancreatology. 2012;12:71-3.

75. DiMagno EP, Malagelada JR, Go VL, Moertel CG. Fate of orally ingested enzymes in pancreatic insufficiency. Comparison of two dosage schedules. N Engl J Med. 1977;296:1318-22.

76. Sikkens ECM, Cahen DL, Kuipers EJ, Bruno MJ. Pancreatic enzyme replacement therapy in chronic pancreatitis. Best Pract Res Clin Gastroenterol. 2010;24:337-47.

77. Domínguez-Muñoz JE. Pancreatic enzyme replacement therapy for pancreatic exocrine insufficiency: when is it indicated, what is the goal and how to do it? Adv Med Sci. 2011;56:1-5.

78. DiMagno MJ, DiMagno EP. Chronic pancreatitis. Curr Opin Gastroenterol. 2005;21:544-54.

79. Domínguez-Muñoz JE, Iglesias-García J, Iglesias-Rey M, Figueiras A Vilariño-Insua M. Effect of the administration schedule on the therapeutic efficacy of oral pancreatic enzyme supplements in patients with exocrine pancreatic insufficiency: A randomized, three-way crossover study. Aliment Pharmacol Ther. 2005;21:993-1000.

80. Borowitz DS, Grand RJ, Durie PR. Use of pancreatic enzyme supplements for patients with cystic fibrosis in the context of fibrosing colonopathy. J Pediatr. 1995:127:681-4.

\section{Submit your next manuscript to BioMed Central and we will help you at every step:}

- We accept pre-submission inquiries

- Our selector tool helps you to find the most relevant journal

- We provide round the clock customer support

- Convenient online submission

- Thorough peer review

- Inclusion in PubMed and all major indexing services

- Maximum visibility for your research

Submit your manuscript at www.biomedcentral.com/submit
Biomed Central 